Murray Stuart (Orcid ID: 0000-0002-5588-2915)

Nagata Jason (Orcid ID: 0000-0002-6541-0604)

Griffiths Scott (Orcid ID: 0000-0002-6366-3560)

\title{
Genetic Risk, Body Mass Index, and Weight Control Behaviors: Unlocking the Triad
}

Short Title: Genetic Risk, BMI, and Weight Control Behaviors

\author{
Jason M. Nagata, MD, $\mathrm{MSc}^{1}$, David B. Braudt, $\mathrm{MS}^{2,3}$, Benjamin W. Domingue, $\mathrm{PhD}^{4}$, \\ Kirsten Bibbins-Domingo, PhD, MD, MAS ${ }^{5,6}$, Andrea K. Garber, PhD, RD ${ }^{1}$, \\ Scott Griffiths, $\mathrm{PhD}^{7}$, Stuart B. Murray, $\mathrm{PhD}^{8}$ \\ ${ }^{1}$ Division of Adolescent and Young Adult Medicine, University of California, San Francisco, San Francisco, CA \\ ${ }^{2}$ Department of Sociology, University of North Carolina at Chapel Hill, Chapel Hill, NC \\ ${ }^{3}$ Carolina Population Center, University of North Carolina at Chapel Hill, Chapel Hill, NC \\ ${ }^{4}$ Graduate School of Education, Stanford University, Stanford, CA \\ ${ }^{5}$ Department of Epidemiology and Biostatistics, University of California, San Francisco, San Francisco, CA \\ ${ }^{6}$ Department of Medicine, University of California, San Francisco, San Francisco, CA \\ ${ }^{7}$ Melbourne School of Psychological Sciences, University of Melbourne, Melbourne, VIC, Australia \\ ${ }^{8}$ Department of Psychiatry, University of California, San Francisco, San Francisco, CA
}

Word Count: 4,318

Corresponding Author:

Jason M. Nagata

$55016^{\text {th }}$ Street, $4^{\text {th }}$ Floor, Box 0110

San Francisco, California 94158

Telephone: +1 (626) 551-1932

E-mail: jasonmnagata@gmail.com

Abstract: 250

Tables: 2

Figures: 1

Supplemental Appendix: 1

Funding: J.M.N. is a participant in the Pediatric Scientist Development Program (K12HD00085033), funded by the American Academy of Pediatrics and the American Pediatric Society, and the Norman Schlossberger Research Fund from the University of California, San Francisco. A.K.G. was supported by the National Institutes of Health (5R01HD082166-02). S.B.M was supported by the National Institutes of Health (K23 MH115184). S.G. is supported by a National Health and Medical Research Council Early Career Fellowship (1121538)

Acknowledgment: Thanks to Eric Vittinghoff and John Boscardin for biostatistical advising and Rebecca Schauer for analytic assistance. This research uses data from Add Health, a program project directed by Kathleen Mullan Harris and designed by J. Richard Udry, Peter S. Bearman, and Kathleen Mullan Harris at the University of North Carolina at Chapel Hill, and funded by grant P01-HD31921 from the Eunice Kennedy Shriver National Institute of Child Health and

This is the author manuscript accepted for publication and has undergone full peer review but has not been through the copyediting, typesetting, pagination and proofreading process, which may lead to differences between this version and the Version of Record. Please cite this article as doi: 10.1002 /eat.23083

This article is protected by copyright. All rights reserved. 
Human Development, with cooperative funding from 23 other federal agencies and foundations. Special acknowledgment is due Ronald R. Rindfuss and Barbara Entwisle for assistance in the original design. Information on how to obtain the Add Health data files is available on the Add Health website (http://www.cpc.unc.edu/addhealth). No direct support was received from grant P01-HD31921 for this analysis.

Conflict of Interest: The authors have no conflicts of interest to disclose.

This article is protected by copyright. All rights reserved. 


\begin{abstract}
Background: The relationship between genetic risk for body mass index (BMI) and weight control behaviors remains unknown. The objectives of this study were to determine the association between genetic risk for BMI and weight control behaviors in young adults, and to examine actual BMI as a potential mediator variable.
\end{abstract}

Methods: We analyzed data from three data collection waves of the National Longitudinal Study of Adolescent to Adult Health. The BMI polygenic score (PGS) was based on published genome-wide association studies for BMI. BMI was collected at 11-18 years and 18-26 years. Weight control behaviors included self-reported: 1) weight loss behaviors (dieting, vomiting, fasting/skipping meals, diet pills, laxatives, or diuretic use to lose weight) and 2) weight gain behaviors (eating more or different foods than normal, taking supplements to gain weight). Results: Among 4,397 participants, the BMI PGS was associated higher odds of weight loss behaviors in females (OR 1.24, 95\% CI 1.14-1.35) and males (OR 1.43, 95\% CI 1.26-1.62), and this association was mediated by BMI (indirect effect 0.04, 95\% CI 0.03-0.05 in females and 0.03, 95\% CI 0.03-0.04 in males). The BMI PGS was associated with lower odds of weight gain behaviors in females and males, which was also mediated by actual BMI.

Conclusions: The BMI PGS was associated with weight loss behaviors in both males and females, and this association was mediated by actual BMI. Clinical interventions to prevent high BMI, particularly for individuals with genetic risk, may also prevent subsequent development of potentially unhealthy weight loss behaviors. 
Keywords: Eating behaviors, disordered eating behaviors, genetics, body mass index, obesity, young adult

This article is protected by copyright. All rights reserved. 


\section{Introduction}

A large proportion of youth at a weight status classified as overweight or obese engage in weight loss behaviors including fasting, skipping meals, vomiting, or taking laxatives or diuretics, which thwart successful weight management and increase future health risks (Ackard, Neumark-Sztainer, Story, \& Perry, 2003; Nagata, Garber, Tabler, Murray, \& Bibbins-Domingo, 2018b; Ogden, Carroll, Fryar, \& Flegal, 2015). By national estimates, 35\% of adolescents and $60 \%$ of adults ages 20-39 are at a weight status classified as overweight or obese by body mass index (BMI) (Ogden, Carroll, Kit, \& Flegal, 2014); of those classified as overweight, 40\% of girls and 20\% of boys engaged in unhealthy weight loss behaviors in the past year (NeumarkSztainer et al., 2007). In addition to interfering with effective weight management, these weight loss behaviors are also associated with increased risk for eating disorders (Striegel-Moore \& Bulik, 2007), which in themselves constitute the leading cause of mortality among people with psychiatric illness (Arcelus, Mitchell, Wales, \& Nielsen, 2011); depression (Neumark-Sztainer, Wall, Larson, Eisenberg, \& Loth, 2011); and significant weight gain over time (NeumarkSztainer et al., 2006).

One important contributor to BMI is genetics. Genome-wide association studies (GWAS) have discovered genetic loci associated with BMI (Locke et al., 2015; Speliotes et al., 2010; Yengo et al., 2018). Single nucleotide polymorphisms (SNPs) discovered in GWAS of BMI phenotypes have relatively small effects; therefore, polygenic scores (PGS) have been used to combine information from multiple GWAS-discovered SNPs (Belsky \& Israel, 2014; Dudbridge, 
2016). A BMI PGS focused on samples of European ancestry has been shown to be predictive of BMI, including in young adults in the US (Belsky et al., 2012; Domingue et al., 2014).

Genetic risk for BMI may also be related to the development of weight loss behaviors. In accord with evidence noting the impact of genetic risk upon BMI, one potential pathway might posit that genetics could lead to higher BMI, and as a consequence of high BMI, individuals then develop weight loss behaviors given the health concerns and stigma associated with overweight and obesity (Golden et al., 2016a). In this putative pathway, genetic architecture would be associated with weight loss behaviors, and BMI would mediate this relationship (Figure 1).

However, another possibility is that genes predisposing to higher BMI may also be linked to broader phenotypes relating to weight loss behaviors, even after accounting for BMI. Pleiotropy, when single genes affect more than one trait (Solovieff, Cotsapas, Lee, Purcell, \& Smoller, 2013), has been demonstrated with certain genes predictive of BMI (Hinney et al., 2017). This was recently substantiated with the identification of three genetic loci that were involved with both BMI and anorexia nervosa (Hinney et al., 2017). However, there has been minimal research on the association between BMI PGS and weight loss behaviors.

Furthermore, the idealized male body image in many Western societies is increasingly large and muscular (Pope, Khalsa, \& Bhasin, 2017); however, research on weight gain goals and behaviors in males is limited (Murry, Griffiths, \& Nagata, 2018). We recently demonstrated that $30 \%$ of U.S. adolescent males reported goals to gain weight with the highest rates (45\%) among adolescent males considered underweight (Nagata et al., 2019); however, this has not been 
examined in relation to BMI PGS. Genetic risk for BMI could be negatively associated with weight gain behaviors, and BMI could mediate this relationship (Figure 1).

The objectives of this study were to examine the association between BMI PGS and weight control behaviors (including weight loss and weight gain behaviors) in young adulthood, and to examine body mass index (BMI) as a potential mediator variable. The public health impact of both BMI and disordered eating is considerable, and a better understanding of the genetic risk architecture may inform joint prevention strategies.

\section{Methods}

\section{Study design and sample}

We used data from three Waves of the National Longitudinal Study of Adolescent to Adult Health (Add Health), a prospective cohort study of adolescents in the United States who were followed into adulthood (Harris et al., 2017). Add Health used a school-based design that selected 80 high schools and a paired middle school representative of US schools with respect to region of country, urbanicity, size, type, and ethnicity. There have been five waves of data collection in Add Health and further details about the study design can be found elsewhere (Harris et al., 2017). For this study, we used restricted-use data from Wave I (1994-1995, 11-18 years old, for BMI), Wave III (2001 to 2002, 18-26 years, when detailed information on eating behaviors was collected) and Wave IV (2008, 24-32 years, when genetic saliva samples were collected).

This article is protected by copyright. All rights reserved. 
For this study, we included all non-genetically related participants in the Add Health cohort who were of European ancestry (given that the BMI PGS was from a GWAS of European-ancestry individuals (Yengo et al., 2018)) and who had genetic data collected in Wave IV. Approximately $77 \%$ of participants in the Wave IV sample consented to providing saliva samples and long-term archiving and genome-wide genotyping. Genetically related individuals were excluded so only one, random, individual per family was included in the analysis. The Genetic relatedness of participants in the Add Health genetic sample was determined using the default cut-offs for identity by descent in PRIMUS, i.e. pi hat $=0.1$ (Staples et al., 2014). Sixtysix participants appeared to be closely related to more individuals than is plausible; these participants were removed from the genotype data. In the remaining 9,974 participants, the genetic relatedness matrix was calculated using the make-rel command in PLINK version 1.9. Identity by descent estimates identified 831 full-sibling pairs irrespective of self-reported kinship or demographic information (Highland, Avery, Duan, Li, \& Harris, 2018). For each of these pairs, one individual was chosen at random to be retained in the sample. We then further restricted the sample to individuals of European ancestry. Principal component (PC) analysis was used to identify respondents in the European ancestry group. To be included in the European ancestry group, individuals must be \pm 1 standard deviation of the mean of the first two PCs of the genetic data estimated from all individuals in the Add Health genome-wide data who selfidentified as non-Hispanic White. Further details on the identification of ancestry groups in Add Health are provided in Braudt and Harris (2018). The University of North Carolina Institutional 
Review Board approved all Add Health study procedures, and the University of California, San Francisco Institutional Review Board deemed this specific project exempt.

\section{Procedures and Quality Control}

For the in-home interviews, an interviewer traveled to the home or another suitable location for the research participants. Written informed consent was obtained from the participant (or their parents if a minor at baseline). Interviews lasted approximately 90 minutes. Computer-assisted self-interview technology was used by participants to answer potentially sensitive questions. At Wave IV, immediately following the interview, interviewers collected biological saliva specimens for buccal cell DNA which was then extracted, quantified, genotyped, and stored at the Institute for Behavioral Genetics in Boulder, CO.

The PGSs used in this study are based on genotyped, rather than imputed, data from Add Health. Genotyping was done on two Illumina platforms (the Human Omni1 Quad BeadChip and the Human Omni2.5 Quad BeadChip) with standard quality control protocols. Specifically, SNPlevel quality control included the removal of all SNPs with improper allele alignment, minor allele frequency $(\mathrm{MAF})<0.5 \%$, call-rates $<90 \%$, triallelic markers, and/or SNPs that did not map on onto chromosomes 1-22 or the sex chromosome. Genetic sex was inferred based on the $\mathrm{X}$ chromosome and checked based on estimates of autosomal heterozygosity (F) as implemented in PLINK. There was >99\% concordance in genetic vs. self-reported sex, with individuals whose F values were between 0.2-0.8, indicating ambiguous sex, being dropped from the sample. Individuals with higher than expected autosomal heterozygosity (based off of PLINK defaults) 
were also dropped. With regards to SNP missingness, 97\% of participants had SNP missingness $<3 \%$. Individuals with SNP missingness $>3 \%$ were excluded. Of over 600,000 variants in the final Add Health genotyped data, 13,721 were removed with a per-variant missing call rate filter of 0.02 . After quality control, there were $N=9,974$ individuals and $N=609,130$ SNPs. For further details about quality control analysis of the Add Health genetic data see (Highland et al., 2018).

\section{Measures}

\section{Independent Variable:}

BMI PGS: The BMI PGS was created by Add Health investigators (Braudt \& Harris, 2018) as a weighted sum of all regression coefficients from a 2018 GWAS meta-analysis conducted by the Genetic Investigation of Anthropometric Traits (GIANT) consortium (Yengo et al., 2018), using the PRSice version 2.1.9 wrapper for R within the PLINK version 1.9 software package (Chang et al., 2015; Euesden, Lewis, \& O'Reilly, 2015) to capture the whole polygenic signal. The metaanalysis was performed on a sample of approximately 700,000 individuals of European ancestry and controlled for age, sex, and 10 genetic PCs and was sex-stratified (Yengo et al., 2018). The PGS was then standardized within ancestry groups to have mean zero and standard deviation of 1. The Add Health cohort was not included in the discovery sample as reported in their supplemental files (Yengo et al., 2018). The PGS for BMI is calculated based on the 609,130 SNPs available in the Add Health genotyped data with clumping at $\mathrm{r}^{2}$ cutoff .1 and $250 \mathrm{~kb}$ window at $\mathrm{p}<1.0$ (Dudbridge, 2016; Wray et al., 2014).

\section{Dependent Variables:}


Weight goals: Participants were asked at 18-26 years (Wave III), “What are you currently doing about your weight?” Response choices included: “trying to lose weight,” "trying to gain weight or bulk up," "trying to stay the same weight," or "not trying to do anything about your weight." “Trying to lose weight” was coded as a weight loss goal. “Trying to gain weight” was coded as a weight gain goal.

Weight loss behaviors: Participants who reported weight loss goals at 18-26 years were then asked, "During the past seven days, which of the following things did you do in order to lose weight or to keep from gaining weight?” Response choices included: 1) dieting, 2) fasted or skipped meals, 3) made yourself throw up, 4) took weight-loss pills, 5) took laxatives, or 6) used diuretics. Those who had affirmative responses to any of 1-6 were coded as engaging in weight loss behaviors. These questions were adapted from validated eating behavior measures such as in the Adolescent Health Survey and similar to Project Eating Among Teens ( $85 \%$ agreement $\geq 1$ behavior, r=0.76) (Neumark-Sztainer, Story, Resnick, \& Blum, 1998; Neumark-Sztainer, 2010), except that the time frame was seven days to be consistent with the seven day time frame of other validated questions in the Add Health survey on nutrition and physical activity.

Weight gain behaviors: Participants who reported weight gain goals at 18-26 years were then asked, "During the past seven days, which of the following things did you do in order to gain weight or bulk up?” Response choices included: 1) ate different foods than usual, 2) ate more, or 3) took food supplements. Those who had affirmative responses to any of 1-3 were coded as engaging in weight gain behaviors. These questions were similarly adapted from validated eating 
behavior measures such as in the Adolescent Health Survey and similar to Project Eating Among Teens (Neumark-Sztainer et al., 1998; Neumark-Sztainer, 2010).

\section{Covariates:}

Ancestry-Specific PCs: Ancestry-specific PCs were calculated from the unrelated European subsample using PLINK version 1.9. PCs were calculated for non-related individuals of European ancestry using the --pca command in PLINK and based on a set of pruned SNPs where linkage disequilibrium pruning was conducted using a window size of $50 \mathrm{~kb}$, a step of 5 variants, and an R-square cutoff of 0.2. We included 10 PCs in all analyses to account for within ancestry population stratification. The use of 10 PCs was based on our reading of the literature and current best practices (Conley et al., 2016; Price et al., 2006; Price, Zaitlen, Reich, \& Patterson, 2010), the meta-analysis which also adjusted for 10 PCs (Yengo et al., 2018), as well as recent work using Add Health genetic data (Belsky et al., 2018).

Eating disorder diagnosis: Participants were asked at 18-26 years, "have you ever been told by a doctor that you have an eating disorder, such as anorexia nervosa or bulimia?” Participants with an affirmative response were coded as having an eating disorder diagnosis.

Body mass index (BMI) was calculated using the standard formula: weight (kilograms) divided by height (meters) squared $\left(\mathrm{BMI}=\right.$ weight/height $\left.{ }^{2}\right)$. Weight $($ Health-o-meter 844KL High Capacity Digital Bathroom Scale; Jarden Corporation; Rye, NY) and height (Carpenter's square, steel tape measure) was measured by the interviewer at age 18-26 years (Wave III). Self-reported height and weight was used for ages 11-18 years (Wave I). Self-reported height and weight have 
been shown to be highly correlated $(r=0.99 ; \mathrm{p}<0.001)$ with objectively measured height and weight (Pursey, Burrows, Stanwell, \& Collins, 2014).

Weight status: Young adults were classified as underweight (BMI <18.5), normal weight (18.5 $\leq \mathrm{BMI}<25)$, overweight $(25 \leq \mathrm{BMI}<30)$, or obese $(\mathrm{BMI} \geq 30)$ in accordance with guidelines from the US Centers for Disease Control and Prevention (Centers for Disease Control, 2012).

\section{Statistical analyses}

Data analyses were performed in 2018 using STATA 15.0. Unadjusted differences between males and females in descriptive characteristics were calculated using independent samples $t$-tests for continuous variables and Pearson's chi-square tests for categorical variables. Logistic regression analyses were used to identify associations of BMI PGS with weight goals and control behaviors, adjusted for PCs and stratified by sex. We added BMI (at 18-26 years, continuous variable) to the models to determine if the effect size of BMI PGS was attenuated after adjusting for this variable.

Additional linear regression models were conducted to test for potential mediation with BMI PGS as the independent variable, BMI (at 18-26 years) as the mediator variable, and weight control behaviors as dependent variables (Figure 1). A bootstrap estimation approach (Preacher \& Hayes, 2004) was used to calculate the point estimate and 95\% confidence interval for the indirect effect, or the amount of mediation (paths a and b in Figure 1). We used the "bootstrap" command in STATA 15.0 (UCLA: Statistical Consulting Group, 2006)) with 1,000 resamples. Significance was indexed at the threshold of $\alpha=.05$, using a Bonferroni correction when 
multiple hypotheses were tested (i.e. $0.05 / 8=0.00625$ for the logistic regression analyses and $0.05 / 4=0.0125$ for the mediation analyses). Analyses scripts are available at https://github.com/jasonmnagata/BMI-Genetic-Risk-and-Weight-Control-Behaviors

\section{Results}

Overall, 4,397 participants (2,395 females and 2,002 males) met inclusion criteria. Descriptive characteristics of the sample are reported in Table 1. A higher proportion of females than males reported weight loss goals and behaviors while a higher proportion of males than females reported weight gain goals and behaviors. Quantile plots of the BMI PGS and outcomes (weight goals, weight control behaviors, and BMI) are shown in the Supplemental Appendix.

BMI PGS was associated with $\mathrm{BMI}$ in both males $(\mathrm{B}=1.74 \pm 0.12, \mathrm{p}<0.001)$ and females ( $\mathrm{B}=1.96 \pm 0.13, \mathrm{p}<0.001$ ), adjusting for 10 PCs. BMI PGS was associated with higher odds of trying to lose weight in females (OR 1.29, 95\% CI 1.18-1.40) and males (OR 1.42, 1.27-1.59, Table 2). BMI PGS was associated with higher odds of weight loss behaviors in females (OR $1.24,1.14-1.35)$ and in males (OR 1.43, 1.26-1.62).

The odds ratio for the association between BMI PGS and weight loss behaviors were attenuated and no longer statistically significant after accounting for BMI (1.24 to 1.06 in females and 1.43 to 1.07 in males), suggesting the relationship may be mediated by BMI (Table 2). Using a bootstrap estimation approach with 1,000 samples, the indirect effect coefficient (the amount of mediation, or the product of paths a and b in Figure 1) was 0.04 (95\% CI 0.03-0.05), $\mathrm{p}<0.001$ for females and 0.03 (95\% CI 0.03-0.04), $\mathrm{p}<0.001$ for males.

This article is protected by copyright. All rights reserved. 
BMI PGS was associated with lower odds of trying to gain weight in females (OR 0.59, 95\% CI 0.46-0.75) and males (OR 0.80, 0.72-0.89, Table 3). BMI PGS was associated with lower odds of weight gain behaviors in females (OR 0.59, 0.45-0.77) and in males (OR 0.79, 0.70-0.88).

The odds ratio for the association between BMI PGS and weight gain behaviors were attenuated and no longer statistically significant after accounting for BMI (0.59 to 0.76 in females and 0.79 to 1.03 in males), suggesting the relationship may be mediated by BMI (Table 3). Using a bootstrap estimation approach with 1,000 samples, the indirect effect coefficient (the amount of mediation, or the product of paths a and b in Figure 1) was -0.01 (95\% CI -0.01- 0.01), $\mathrm{p}<0.001$ for females and -0.03 (95\% CI -0.04- -0.03), $\mathrm{p}<0.001$ for males.

\section{Sensitivity Analyses}

Several sensitivity analyses are reported in the Supplemental Appendix. We tested the association between BMI PGS and BMI at ages 11-18. We performed sensitivity analyses with BMI PGS based on varying $\mathrm{p}$-value thresholds $(\mathrm{p}<0.1, \mathrm{p}<0.01, \mathrm{p}<0.001)$, excluding participants with an eating disorder diagnosis, adjusting for varying numbers of PCs, and adjusting for school clustering, demonstrating similar results. In an additional sensitivity analysis, we created a sum of number of weight loss behaviors (0-6) variable (rather than a binary variable), which approximated a negative binomial distribution. We conducted negative binomial regression between BMI PGS (independent variable) with weight loss behaviors (dependent variable), 
adjusted for PCs and BMI (18-26 years), and stratified by sex. These results had similar findings to the logistic regression with the binary weight loss behavior outcome variable. We also used BMI at 11-18 years and BMI change from 11-18 to 18-26 years (rather than BMI at 18-26 years) as the mediator variable so that the mediator variable would be temporally before the outcome (weight control behaviors). We repeated the bootstrapping method using BMI at 11-18 years and BMI change from 11-18 to 18-26 years as the mediator variable and found similar results to the mediation test using BMI at 18-26 years.

\section{Discussion}

The present study investigates the relationship between genetic risk for BMI and weight control behaviors. In our sample, the genetic risk for BMI was associated with weight loss behaviors in both female and male young adults. This relationship was mediated by BMI and no significant independent association between genetic risk for BMI and weight loss behaviors was observed after adjusting for BMI. These findings indicate mechanisms that may inform interventions to prevent potentially unhealthy weight loss behaviors.

Our findings demonstrate that BMI may be an important pathway linking genetics to weight loss behaviors, as demonstrated by the mediation analysis. In this model, genetic variants associated with BMI were positively associated with actual measured BMI, which also was associated with weight loss behaviors. There is growing literature linking genetics to BMI (Locke et al., 2015; Speliotes et al., 2010; Yengo et al., 2018), and the BMI PGS used in this 
study is significantly associated with young adult BMI (Figure 1, a). Population-based epidemiologic studies suggest that those of greater bodyweight are more likely to engage in potentially unhealthy weight loss behaviors such as vomiting, fasting or skipping meals, or using laxatives or diuretics (Nagata et al., 2018b; Neumark-Sztainer et al., 2007) (Figure 1, b). Higher BMI is also associated with higher rates of dieting, especially in females (Neumark-Sztainer et al., 2007). This may be due to poor body image, and societal or environmental pressures for a thin body ideal, particularly in females (Bozsik, Whisenhunt, Hudson, Bennett, \& Lundgren, 2018). Our study links these two pathways (Figure 1, a and b), suggesting that the association between BMI genetic risk and engagement in weight loss behaviors is mediated through actual BMI. This is consistent with previous work showing that many individuals reach above-average BMIs before the development of an eating disorder (Swenne, 2016). Higher premorbid BMI also predicted which individuals with anorexia nervosa developed the binge/purge variant of anorexia nervosa over the subsequent 18 years (Lantz, Gillberg, Råstam, Wentz, \& Lowe, 2017).

This mechanism mediated by BMI may also have particular clinical relevance for the development of atypical anorexia nervosa, a diagnosis where individuals meet psychological criteria for anorexia nervosa, but whose weight is within or above the normal range (American Psychiatric Association, 2013). Some individuals with atypical anorexia nervosa may develop weight loss behaviors in the context of a high BMI in attempts to lose weight (Nagata, Garber, \& Buckelew, 2018). We previously reported that risk factors for weight loss behaviors differ by sex and weight status (Nagata, Garber, Tabler, Murray, \& Bibbins-Domingo, 2018a). While certain 
adolescent family, community, and environmental factors predicted weight loss behaviors in underweight or normal weight females, these same risk factors did not apply to females considered overweight or obese (Nagata et al., 2018a). Here we find a potential mechanism that may explain the development of weight loss behaviors in young adults who are considered overweight or obese.

Previous work has identified three genetic loci that were involved with both BMI and anorexia nervosa (Hinney et al., 2017), indicating the potential for pleiotropy, when single genes may have two or more unrelated effects. However, when adjusting for BMI, we found that genetic risk for BMI was no longer independently associated with weight loss behaviors. Thus we did not find evidence for pleiotropy in this BMI PGS. Rather than examining genetic links to BMI and subsequent weight loss behaviors, twin studies have examined heritability and genetic correlations of traits directly related to intentional weight loss (Wade, Treloar, Heath, \& Martin, 2009).

The finding that BMI mediates the relationship between BMI PGS and weight loss behaviors has clinical implications for the prevention of both high BMI and weight loss behaviors. Efforts to prevent high BMI may also prevent the development of subsequent weight loss behaviors, many of which have adverse health effects (Golden et al., 2016b; Striegel-Moore \& Bulik, 2007). Not all individuals in the Add Health sample with genetic variants associated with BMI developed a higher BMI in adolescence or young adulthood, so these outcomes are potentially responsive to environmental factors, behavior change, and interventions. However, 
the development of effective prevention and treatment interventions for high BMI remains a persistent challenge (Reinehr, 2013). Furthermore, most dieters may be motivated to avoid weight gain and overweight whereas individuals with bulimia are also motivated by a desire to reach an objective state of thinness (Chernyak \& Lowe, 2010). Dieting may be driven by a predisposition toward weight gain, such as from genetic variants associated with BMI, but does not itself cause weight gain or obesity (Lowe, 2015).

The prevalence of weight loss behaviors was more than twice as high in females compared to males; however, the prevalence of weight gain behaviors was over six times higher in males compared to females. This finding may underscore the qualitatively different nature of weight control behaviors typically engaged in by males. Males may report a desire for greater weight and a pursuit of greater muscularity, which may result in weight gain behaviors such as supplement use and excessive consumption of protein (Murray et al., 2017). We found that genetic variants associated with BMI were negatively associated with weight gain behaviors in males and females, and this association was also mediated by actual measured BMI. To our knowledge, this is one of the first studies to examine genetic links to weight gain goals and behaviors. Future research may examine genetic links to potentially unhealthy muscle-building behaviors such as androgenic anabolic steroid use (Pope et al., 2014). The complex intersection between genetic risk, BMI, and weight control behaviors could be further delineated as it relates to both males and females.

\section{Limitations}


We acknowledge several limitations. Our study population of young adults with European ancestry may not be generalizable to other ancestries; however, the BMI PGS was based on studies from samples with European ancestry (Yengo et al., 2018). Relatedness between samples cannot be completely ruled out as we were unable to calculate a relatedness matrix between the Add Health sample and the whole Yengo et al. (2018) BMI GWAS sample. Behaviors were based on self-report, a method that may be subject to reporting bias. However, self-reported height and weight have been shown to be highly correlated ( $r=0.99 ; \mathrm{p}<0.001)$ with objectively measured height and weight (Pursey et al., 2014). The response timeframe assessed in our measure of weight control behaviors in Add Health was shorter (only past seven days) than the timeframe of other measures, including the EDE-Q (past 28 days) (Fairburn \& Beglin, 2008). Thus, our study may have underestimated or overestimated the prevalence of weight loss behaviors compared to studies based on the EDE-Q or similar measures. Because dieting was more common than more severe extreme weight control behaviors such as vomiting and laxative abuse, the results may be more relevant to the cause of dieting than to the cause of disordered eating per se. Though participants were asked about a prior eating disorder diagnosis at Wave III, we did not have data on specific diagnosis, age of onset, current presence of symptoms, or receipt of treatment. Notable strengths of our study included a large sample, inclusion of both males and females, and objective measures of genetic risk using the most recently available BMI PGS through Add Health based on a 2018 published GWAS (Yengo et al., 2018). 


\section{Conclusion}

Genetic risk for BMI was associated with weight loss behaviors in both males and females, and this association was mediated by BMI. Clinical interventions to prevent higher BMI, particularly for individuals with genetic risk, may also prevent subsequent development of potentially unhealthy weight loss behaviors. Our study adds to the scant literature on the relationship between genetic risk and weight loss behaviors, identifying an important pathway through actual BMI. Genetic risk for BMI was negatively associated with weight gain behaviors, which was also mediated by BMI. Future research should examine how genetics and the environment may interact to influence BMI and weight control behaviors longitudinally from adolescence to adulthood.

Figure 1. Mediation analysis model for BMI polygenic score, actual measured BMI, and weight control behaviors. 


\section{References}

Ackard, D. M., Neumark-Sztainer, D., Story, M., \& Perry, C. (2003). Overeating among adolescents: Prevalence and associations with weight-related characteristics and psychological health. Pediatrics, 111(1), 67-74.

American Psychiatric Association. (2013). Diagnostic and statistical manual of mental disorders (5th Ed. ed.). Arlington, VA: American Psychiatric Publishing.

Arcelus, J., Mitchell, A. J., Wales, J., \& Nielsen, S. (2011). Mortality rates in patients with anorexia nervosa and other eating disorders. A meta-analysis of 36 studies. Archives of General Psychiatry, 68(7), 724-731. doi:10.1001/archgenpsychiatry.2011.74 [doi]

Belsky, D. W., \& Israel, S. (2014). Integrating genetics and social science: Genetic risk scores. Biodemography and Social Biology, 60(2), 137-155. doi:10.1080/19485565.2014.946591 [doi]

Belsky, D. W., Moffitt, T. E., Houts, R., Bennett, G. G., Biddle, A. K., Blumenthal, J. A., . . Caspi, A. (2012). Polygenic risk, rapid childhood growth, and the development of obesity: Evidence from a 4-decade longitudinal study. Archives of Pediatrics \& Adolescent Medicine, 166(6), 515-521. doi:10.1001/archpediatrics.2012.131 [doi]

Belsky, D. W., Domingue, B. W., Wedow, R., Arseneault, L., Boardman, J. D., Caspi, A., .. . Harris, K. M. (2018). Genetic analysis of social-class mobility in five longitudinal studies. Proceedings of the National Academy of Sciences of the United States of America, 115(31), E7284. doi:10.1073/pnas.1801238115

Bozsik, F., Whisenhunt, B. L., Hudson, D. L., Bennett, B., \& Lundgren, J. D. (2018). Thin is in? think again: The rising importance of muscularity in the thin ideal female body. Sex Roles, doi:10.1007/s11199-017-0886-0

Braudt, D. B., \& Harris, K. M. (2018). Polygenic scores (PGSs) in the national longitudinal study of adolescent to adult health (add health) - release 1 . Retrieved from http://www.dx.doi.org/10.17615/C6M372

Centers for Disease Control. (2012). Defining adult overweight and obesity. (). Retrieved from http://www.cdc.gov/obesity/adult/defining.html

This article is protected by copyright. All rights reserved. 
Chang, C. C., Chow, C. C., Tellier, L. C., Vattikuti, S., Purcell, S. M., \& Lee, J. J. (2015). Second-generation PLINK: Rising to the challenge of larger and richer datasets. GigaScience, 4, 7. doi:10.1186/s13742-015-0047-8

Chernyak, Y., \& Lowe, M. R. (2010). Motivations for dieting: Drive for thinness is different from drive for objective thinness. Journal of Abnormal Psychology, 119(2), 276-281. doi:10.1037/a0018398

Conley, D., Laidley, T., Belsky, D. W., Fletcher, J. M., Boardman, J. D., \& Domingue, B. W. (2016). Assortative mating and differential fertility by phenotype and genotype across the 20th century. Proceedings of the National Academy of Sciences of the United States of America, 113(24), 6647-6652. doi:10.1073/pnas.1523592113

Domingue, B. W., Belsky, D. W., Harris, K. M., Smolen, A., McQueen, M. B., \& Boardman, J. D. (2014). Polygenic risk predicts obesity in both white and black young adults. PloS One, 9(7), e101596. doi:10.1371/journal.pone.0101596 [doi]

Dudbridge, F. (2016). Polygenic epidemiology. Genetic Epidemiology, 40(4), 268-272. doi:10.1002/gepi.21966 [doi]

Euesden, J., Lewis, C. M., \& O'Reilly, P. F. (2015). PRSice: Polygenic risk score software. Bioinformatics (Oxford, England), 31(9), 1466-1468. doi:10.1093/bioinformatics/btu848

Fairburn, C. G., \& Beglin, S. (2008). Eating disorder examination questionnaire. In C. G. Fairburn (Ed.), Cognitive behavior therapy and eating disorders (pp. 309-313). New York: Guilford Press.

Golden, N. H., Schneider, M., Wood, C., COMMITTEE ON NUTRITION, COMMITTEE ON ADOLESCENCE, \& SECTION ON OBESITY. (2016a). Preventing obesity and eating disorders in adolescents. Pediatrics, 138(3), 1649. Epub 2016 Aug 22.

doi:10.1542/peds.2016-1649 [doi]

Golden, N. H., Schneider, M., Wood, C., COMMITTEE ON NUTRITION, COMMITTEE ON ADOLESCENCE, \& SECTION ON OBESITY. (2016b). Preventing obesity and eating disorders in adolescents. Pediatrics, 138(3), 1649. Epub 2016 Aug 22. doi:10.1542/peds.2016-1649 [doi]

Harris, K. M., Halpern, C. T., Whitsel, E., Hussey, J., Tabor, J., Entzel, P. \& Udry, J. R. (2017). The national longitudinal study of adolescent to adult health: Research design. Retrieved from https://www.cpc.unc.edu/projects/addhealth/design/researchdesign_3618_regular.pdf

This article is protected by copyright. All rights reserved. 
Highland, H. M., Avery, C. L., Duan, Q., Li, Y. \& Harris, K. M. (2018). Quality control analysis of add health GWAS data.

Hinney, A., Kesselmeier, M., Jall, S., Volckmar, A. L., Focker, M., Antel, J., . . Hebebrand, J. (2017). Evidence for three genetic loci involved in both anorexia nervosa risk and variation of body mass index. Molecular Psychiatry, 22(2), 192-201. doi:10.1038/mp.2016.71 [doi]

Lantz, E. L., Gillberg, C., Råstam, M., Wentz, E., \& Lowe, M. R. (2017). Premorbid BMI predicts binge-purge symptomatology among individuals with anorexia nervosa. The International Journal of Eating Disorders, 50(7), 852-855. doi:10.1002/eat.22718

Locke, A. E., Kahali, B., Berndt, S. I., Justice, A. E., Pers, T. H., Day, F. R., . . Speliotes, E. K. (2015). Genetic studies of body mass index yield new insights for obesity biology. Nature, 518(7538), 197-206. doi:10.1038/nature14177 [doi]

Lowe, M. R. (2015). Dieting: Proxy or cause of future weight gain? Obesity Reviews: An Official Journal of the International Association for the Study of Obesity, 16 Suppl 1, 19-24. doi:10.1111/obr.12252

Murray, S. B., Nagata, J. M., Griffiths, S., Calzo, J. P., Brown, T. A., Mitchison, D., . . Mond, J. M. (2017). The enigma of male eating disorders: A critical review and synthesis. Clinical Psychology Review, 57, 1-11. doi:S0272-7358(17)30137-X [pii]

Murry, S. B., Griffiths, S., \& Nagata, J. M. (2018). Community-based eating disorder research in males: A call to action. Journal of Adolescent Health, 62(6), 649-50.

doi://doi.org/10.1016/j.jadohealth.2018.03.008

Nagata, J. M., Bibbins-Domingo, K., Garber, A. K., Griffiths, S., Vittinghoff, E., \& Murray, S. B. (2019). Boys, bulk, and body ideals: Sex differences in weight gain attempts among adolescents in the united states. J Adolesc Health, 64(4), 450-453.

Nagata, J. M., Garber, A. K., \& Buckelew, S. M. (2018). Weight restoration in atypical anorexia nervosa: A clinical conundrum. International Journal of Eating Disorders, 51(11), 1290-93.

Nagata, J. M., Garber, A. K., Tabler, J., Murray, S. B., \& Bibbins-Domingo, K. (2018a). Differential risk factors for unhealthy weight control behaviors by sex and weight status among U.S. adolescents. J Adolesc Health, 63(3), 335-341. Retrieved from 10.1016/j.jadohealth.2018.03.022

This article is protected by copyright. All rights reserved. 
Nagata, J. M., Garber, A. K., Tabler, J., Murray, S. B., \& Bibbins-Domingo, K. (2018b). Prevalence and correlates of disordered eating behaviors among young adults with overweight or obesity. Journal of General Internal Medicine, 33(8), 1337-1343.

Neumark-Sztainer, D. (2010). Project EAT 2010 and F-EAT surveys - derived variables and scales. Retrieved from http://docs.sph.umn.edu/epich/eat/EAT2010_FEAT_Psychometrics.pdf

Neumark-Sztainer, D., Story, M., Resnick, M. D., \& Blum, R. W. (1998). Lessons learned about adolescent nutrition from the minnesota adolescent health survey. Journal of the American Dietetic Association, 98(12), 1449-1456. doi:S0002-8223(98)00329-0 [pii]

Neumark-Sztainer, D., Wall, M. M., Haines, J. I., Story, M. T., Sherwood, N. E., \& van den Berg, P A. (2007). Shared risk and protective factors for overweight and disordered eating in adolescents. American Journal of Preventive Medicine, 33(5), 359-369. doi:S07493797(07)00498-9 [pii]

Neumark-Sztainer, D., Wall, M., Guo, J., Story, M., Haines, J., \& Eisenberg, M. (2006). Obesity, disordered eating, and eating disorders in a longitudinal study of adolescents: How do dieters fare 5 years later? Journal of the American Dietetic Association, 106(4), 559-568. doi:S0002-8223(06)00004-6 [pii]

Neumark-Sztainer, D., Wall, M., Larson, N. I., Eisenberg, M. E., \& Loth, K. (2011). Dieting and disordered eating behaviors from adolescence to young adulthood: Findings from a 10-year longitudinal study. Journal of the American Dietetic Association, 111(7), 1004-1011. doi:10.1016/j.jada.2011.04.012 [doi]

Ogden, C. L., Carroll, M. D., Fryar, C. D., \& Flegal, K. M. (2015). Prevalence of obesity among adults and youth: United states, 2011-2014. NCHS Data Brief, (219)(219), 1-8.

Ogden, C. L., Carroll, M. D., Kit, B. K., \& Flegal, K. M. (2014). Prevalence of childhood and adult obesity in the united states, 2011-2012. Jama, 311(8), 806-814.

doi:10.1001/jama.2014.732 [doi]

Pope, H. G.,Jr, Khalsa, J. H., \& Bhasin, S. (2017). Body image disorders and abuse of anabolicandrogenic steroids among men. Jama, 317(1), 23-24. doi:10.1001/jama.2016.17441 [doi]

Pope, H. G.,Jr, Wood, R. I., Rogol, A., Nyberg, F., Bowers, L., \& Bhasin, S. (2014). Adverse health consequences of performance-enhancing drugs: An endocrine society scientific statement. Endocrine Reviews, 35(3), 341-375. doi:10.1210/er.2013-1058 [doi]

This article is protected by copyright. All rights reserved. 
Preacher, K. J., \& Hayes, A. F. (2004). SPSS and SAS procedures for estimating indirect effects in simple mediation models. Behavior Research Methods, Instruments, \& Computers, 36(4), 717-731. doi:10.3758/BF03206553

Price, A. L., Patterson, N. J., Plenge, R. M., Weinblatt, M. E., Shadick, N. A., \& Reich, D. (2006). Principal components analysis corrects for stratification in genome-wide association studies. Nature Genetics, 38(8), 904-909. doi:10.1038/ng1847

Price, A. L., Zaitlen, N. A., Reich, D., \& Patterson, N. (2010). New approaches to population stratification in genome-wide association studies. Nature Reviews. Genetics, 11(7), 459-463. doi:10.1038/nrg2813

Pursey, K., Burrows, T. L., Stanwell, P., \& Collins, C. E. (2014). How accurate is web-based self-reported height, weight, and body mass index in young adults? Journal of Medical Internet Research, 16(1), e4. doi:10.2196/jmir.2909 [doi]

Reinehr, T. (2013). Lifestyle intervention in childhood obesity: Changes and challenges. Nature Reviews. Endocrinology, 9(10), 607-614. doi:10.1038/nrendo.2013.149

Solovieff, N., Cotsapas, C., Lee, P. H., Purcell, S. M., \& Smoller, J. W. (2013). Pleiotropy in complex traits: Challenges and strategies. Nature Reviews.Genetics, 14(7), 483-495. doi:10.1038/nrg3461 [doi]

Speliotes, E. K., Willer, C. J., Berndt, S. I., Monda, K. L., Thorleifsson, G., Jackson, A. U., . . . Loos, R. J. (2010). Association analyses of 249,796 individuals reveal 18 new loci associated with body mass index. Nature Genetics, 42(11), 937-948. doi:10.1038/ng.686 [doi]

Staples, J., Qiao, D., Cho, M. H., Silverman, E. K., Nickerson, D. A., \& Below, J. E. (2014). PRIMUS: Rapid reconstruction of pedigrees from genome-wide estimates of identity by descent. American Journal of Human Genetics, 95(5), 553-564. doi:10.1016/j.ajhg.2014.10.005

Striegel-Moore, R. H., \& Bulik, C. M. (2007). Risk factors for eating disorders. The American Psychologist, 62(3), 181-198. doi:2007-04834-005 [pii]

Swenne, I. (2016). Influence of premorbid BMI on clinical characteristics at presentation of adolescent girls with eating disorders. BMC Psychiatry, 16, 81. doi:10.1186/s12888-0160788-7

This article is protected by copyright. All rights reserved. 
UCLA: Statistical Consulting Group. (2006). How to perform sobel-goodman mediation tests in stata? | stata FAQ. Retrieved from https://stats.idre.ucla.edu/stata/faq/how-to-perform-sobelgoodman-mediation-tests-in-stata/

Wade, T. D., Treloar, S. A., Heath, A. C., \& Martin, N. G. (2009). An examination of the overlap between genetic and environmental risk factors for intentional weight loss and overeating. The International Journal of Eating Disorders, 42(6), 492-497. doi:10.1002/eat.20668 [doi]

Wray, N. R., Lee, S. H., Mehta, D., Vinkhuyzen, A. A. E., Dudbridge, F., \& Middeldorp, C. M. (2014). Research review: Polygenic methods and their application to psychiatric traits. Journal of Child Psychology and Psychiatry, and Allied Disciplines, 55(10), 1068-1087. doi:10.1111/jcpp.12295

Yengo, L., Sidorenko, J., Kemper, K. E., Zheng, Z., Wood, A. R., Weedon, M. N., .. . Visscher, P. M. (2018). Meta-analysis of genome-wide association studies for height and body mass index in 700000 individuals of european ancestry. Human Molecular Genetics, 27(20), 3641-3649. doi:10.1093/hmg/ddy271

This article is protected by copyright. All rights reserved. 
Table 1. Descriptive characteristics of young adults in the National Longitudinal Study of Adolescent to Adult Health

\begin{tabular}{|c|c|c|c|}
\hline \multirow[b]{2}{*}{$\mathrm{N}$} & Female & Male & \multirow[b]{3}{*}{$\mathrm{p}$} \\
\hline & 2,395 & 2,002 & \\
\hline & $\begin{array}{c}\text { Mean } \pm \text { SD or } \\
\%\end{array}$ & $\begin{array}{l}\text { Mean } \pm \text { SD } \\
\text { or } \%\end{array}$ & \\
\hline \multicolumn{4}{|c|}{ Young adult measures (18-26 years, Wave III) } \\
\hline Age (years) & $21.76 \pm 1.78$ & $21.96 \pm 1.75$ & $<0.001$ \\
\hline Body mass index $\left(\mathrm{kg} / \mathrm{m}^{2}\right)$ & $26.08 \pm 6.63$ & $26.11 \pm 5.54$ & 0.895 \\
\hline Weight status & & & $<0.001$ \\
\hline Underweight (BMI <18.5) & $4.1 \%$ & $2.2 \%$ & \\
\hline Normal weight $(18.5 \leq \mathrm{BMI}<25)$ & $48.7 \%$ & $44.8 \%$ & \\
\hline Overweight $(25 \leq \mathrm{BMI}<30)$ & $21.0 \%$ & $29.5 \%$ & \\
\hline Obese (BMI $\geq 30)$ & $26.2 \%$ & $23.5 \%$ & \\
\hline Weight loss goals & $45.4 \%$ & $19.7 \%$ & $<0.001$ \\
\hline Weight gain goals & $3.1 \%$ & $23.3 \%$ & $<0.001$ \\
\hline Weight loss behaviors $^{\mathrm{a}}$ & $36.8 \%$ & $14.8 \%$ & $<0.001$ \\
\hline Dieted & $28.9 \%$ & $10.6 \%$ & $<0.001$ \\
\hline Fasted or skipped meals & $11.6 \%$ & $5.4 \%$ & $<0.001$ \\
\hline Made yourself throw up & $0.4 \%$ & $0.1 \%$ & 0.015 \\
\hline Weight loss pills & $5.8 \%$ & $1.6 \%$ & $<0.001$ \\
\hline Laxatives & $0.4 \%$ & $0.0 \%$ & 0.006 \\
\hline Diuretics & $0.5 \%$ & $0.1 \%$ & 0.006 \\
\hline Weight gain behaviors ${ }^{\mathrm{b}}$ & $2.7 \%$ & $16.8 \%$ & $<0.001$ \\
\hline Ate more & $2.3 \%$ & $12.3 \%$ & $<0.001$ \\
\hline Ate different foods than usual & $1.3 \%$ & $5.8 \%$ & $<0.001$ \\
\hline Took food supplements & $0.4 \%$ & $7.0 \%$ & $<0.001$ \\
\hline Eating disorder diagnosis (self-report) & $5.2 \%$ & $0.5 \%$ & $<0.001$ \\
\hline
\end{tabular}

${ }^{a}$ Weight control behaviors include dieting, vomiting, fasting/skipping meals, or laxative/diuretic use to lose weight

${ }^{\mathrm{b}}$ Weight gain behaviors include eating more, eating different foods than normal, and taking food supplements to gain weight

This article is protected by copyright. All rights reserved. 
Table 2. Logistic regression of BMI genetic risk score (clumping at $r^{2}$ cutoff .1 and $250 \mathrm{~kb}$ window including 10 $\mathrm{p}<1.0)$ as predictor and weight loss goals and behaviors as outcomes

\begin{tabular}{|c|c|c|c|c|c|}
\hline & \multicolumn{3}{|c|}{ Females } & \multicolumn{2}{|c|}{ Males } \\
\hline & OR (95\% CI) & $\mathrm{p}$ & pseudo $\mathrm{R}^{2}$ & OR (95\% CI) & $\mathrm{p}$ \\
\hline Weight loss goals & $1.29(1.18-1.40)$ & $<0.001$ & 0.02 & 1.42 (1.27-1.59) & $<0.001$ \\
\hline Weight loss behaviors $^{\mathrm{a}}$ & $1.24(1.14-1.35)$ & $<0.001$ & 0.01 & $1.43(1.26-1.62)$ & $<0.001$ \\
\hline \multicolumn{6}{|l|}{ Adjusted for $\mathrm{BMI}^{\mathrm{b}}$} \\
\hline Weight loss goals & $1.03(0.94-1.13)$ & 0.56 & 0.11 & $1.00(0.88-1.14)$ & 0.97 \\
\hline Weight loss behaviors $^{\mathrm{a}}$ & $1.06(0.96-1.16)$ & 0.24 & 0.06 & $1.07(0.92-1.23)$ & 0.38 \\
\hline
\end{tabular}

Bold indicates $\mathrm{p}<0.00625$ (Bonferroni correction)

a Weight loss behaviors include dieting, vomiting, fasting/skipping meals, or laxative/diuretic use to lose weight

${ }^{\mathrm{b}}$ BMI is significantly associated with all outcomes in both sexes $(\mathrm{p}<0.001)$ 
Table 3. Logistic regression of BMI genetic risk score (clumping at r2 cutoff .1 and $250 \mathrm{~kb}$ window including 10 $\mathrm{p}<1.0)$ as predictor and weight gain goals and behaviors as outcomes

\begin{tabular}{|c|c|c|c|c|c|}
\hline & \multicolumn{3}{|c|}{ Females } & \multicolumn{2}{|c|}{ Males } \\
\hline & OR (95\% CI) & $\mathrm{p}$ & pseudo $\mathrm{R}^{2}$ & OR (95\% CI) & $\mathrm{p}$ \\
\hline Weight gain goals & $0.59(0.46-0.75)$ & $<0.001$ & 0.03 & $0.80(0.72-0.89)$ & $<0.001$ \\
\hline Weight gain behaviorsa & $0.59(0.45-0.77)$ & $<0.001$ & 0.03 & $0.79(0.70-0.88)$ & $<0.001$ \\
\hline Adjusted for $\mathrm{BMI}^{\mathrm{b}}$ & & & & & \\
\hline Weight gain goals & $0.76(0.58-1.00)$ & 0.05 & 0.17 & $1.02(0.91-1.14)$ & 0.76 \\
\hline Weight gain behaviorsa & $0.76(0.57-1.02)$ & 0.07 & 0.17 & $1.03(0.91-1.18)$ & 0.63 \\
\hline
\end{tabular}

Bold indicates $\mathrm{p}<0.00625$ (Bonferroni correction)

${ }^{a}$ Weight gain behaviors include eating more, eating different foods than normal, and taking food supplements to gain weight

${ }^{\mathrm{b}}$ BMI is significantly associated with all outcomes in both sexes $(\mathrm{p}<0.001)$ 


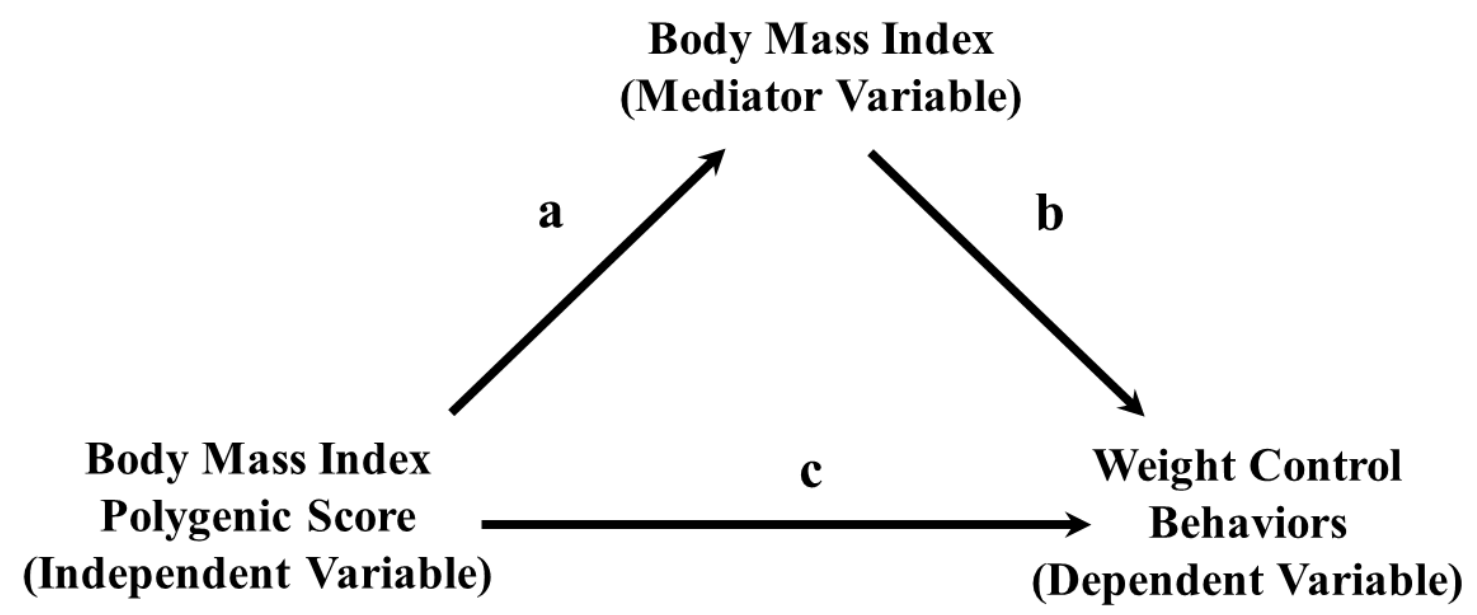

This article is protected by copyright. All rights reserved. 


\section{University Library}

\section{- M I N E R VA \\ A gateway to Melbourne's research publications}

Minerva Access is the Institutional Repository of The University of Melbourne

\section{Author/s:}

Nagata, JM;Braudt, DB;Domingue, BW;Bibbins-Domingo, K;Garber, AK;Griffiths, S;Murray, SB

Title:

Genetic risk, body mass index, and weight control behaviors: Unlocking the triad

Date:

2019-07-01

\section{Citation:}

Nagata, J. M., Braudt, D. B., Domingue, B. W., Bibbins-Domingo, K., Garber, A. K., Griffiths, S. \& Murray, S. B. (2019). Genetic risk, body mass index, and weight control behaviors: Unlocking the triad. INTERNATIONAL JOURNAL OF EATING DISORDERS, 52 (7), pp.825-833. https://doi.org/10.1002/eat.23083.

Persistent Link:

http://hdl.handle.net/11343/285759 